\title{
Diz Eklem Protezlerinde Kullanılan UHMWPE Insert Bileşeni için Aşınma Durumunun Diz Eklem Protezi Aşınma Test Simülatörü İle İncelenmesi
}

\author{
Investigation of the Wear Condition for the UHMWPE Insert Component Used in Knee \\ Joint Prosthesis with Knee Joint Prosthesis Wear Test Simulator
}

\author{
Ender EMIR* ${ }^{* 1, a}$, Erkan BAHÇE ${ }^{2, b}$, Mehmet Sami GÜLER ${ }^{3, c}$ \\ ${ }^{I}$ Kahramanmaraș İstiklal Üniversitesi, Elbistan MYO, Otomotiv Teknolojileri Programı, Kahramanmaraș \\ ${ }^{2}$ Inönü Üniversitesi, Mühendislik Fakültesi, Makine Mühendisliği Bölümü, Malatya \\ ${ }^{3}$ Ordu Üniversitesi, TBMYO, Makine ve Metal Teknolojileri Bölümü, Ordu
}

• Geliş tarihi / Received: 29.03.2019 • Düzeltilerek geliş tarihi / Received in revised form: 19.09.2019 • Kabul tarihi / Accepted: 27.09 .2019

\begin{abstract}
$\ddot{\mathbf{O} z}$
Günümüzde bireylerin diz ekleminde trafik kazaları, spor yaralanmaları ve kıkırdak yapısında meydana gelen deformasyon sonucunda cerrahi operasyonlarda diz eklem protezleri yoğun olarak kullanılmaktadır. Ancak kullanım şartlarına bağlı olarak protez bileşenlerinde oluşabilecek hataların belirlenebilmesi gerekmektedir. Bu çalışmada kullanım esnasında diz eklem protez bileşenlerinden biri olan yüksek moleküler yoğunluklu ultra hafif polietilen (UHMWPE) insert bileşeninde meydana gelen hata durumlarının gözlemlenebilmesi amaçlandı. Bu nedenle diz simülatörü ile aşınma testi $1 \times 10^{6}, 2 \times 10^{6}$ ve $3 \times 10^{6}$ olmak üzere üç farklı çevrim sayısında gerçekleştirildi. Testlerin sonunda UHMWPE insert medial ve lateral kondillerden mikroskop görüntüleri ve kütle kaybı ölçümleri alındı. Elde edilen bulgularda çevrim sayısının artışına bağlı olarak UHMWPE insert bileşeni üzerinde farklı eksenlerdeki tekrarlı kuvvetler sonucunda çukurcuk aşınmalarının, kılcal çatlakların, çiziklerin, yığılmış partiküllerin ve kütle kayıplarının belirgin bir şekilde oluştuğu görüldü.
\end{abstract}

Anahtar kelimeler: Diz Eklem Protezi, Kütle Kaybı, UHMWPE Insert, Yüzey Kalitesi

\begin{abstract}
Today, knee joint prosthesis is used extensively in surgical operations as a result of traffic accidents, sports injuries and in the deformation of the cartilage structure in the knee joint of individuals. However, depending on the conditions of use, it is necessary to determine the defects that may occur in the prosthetic components. In this study, it is aimed to observe the error mechanisms of ultra high molecular weight polyethylene (UHMWPE) insert component which is one of the knee joint prosthesis components during use. Therefore, the wear test with knee simulator was carried out in three different cycles; $1 \times 10^{6}, 2 \times 10^{6}$ and $3 \times 10^{6}$. At the end of the tests, microscop images and mass loss measurements were taken from the medial and lateral condyles of the UHMWPE insert. According to the results, it is seen that due to the increase in the number of cycles, it is seen that pitting wear, capillary cracks, scratches, agglomerated particles and mass losses occur as a result of repetitive forces on different axes on UHMWPE insert component.
\end{abstract}

Keywords: Knee Joint Prosthesis, Mass Loss, UHMWPE Insert, Surface Quality

\footnotetext{
*a Ender EMIR; enderemir.inonu@ gmail.com, orcid.org/0000-0003-4972-5064

${ }^{b}$ orcid.org/0000-0001-5389-5571 ${ }^{\mathrm{c}}$ orcid.org/0000-0003-0414-7707
} 


\section{Giriş}

Vücudun en büyük eklemi olma özelliğini taşıyan diz eklemi vücut ağırlığı başta olmak üzere, günlük aktivitelere bağlı olarak dinamik kuvvetlere maruz kalmaktadır. Etkisi altında kaldığı kuvvetler sonucunda belli bir süre sonra diz ekleminde problemler meydana gelmektedir. $\mathrm{Bu}$ problemlerin en başında diz ekleminin birbiri ile uyumlu bir şekilde hareket etmesine yardımc1 olan eklem kıkırdağının yapısının bozulmasıdır. Eklem kıkırdağındaki bu bozulma sonucunda kemik yüzeyleri birbirini aşındırmaya başlamaktadır. Kemik yüzeylerindeki aşınma ile birlikte diz eklemi eski işlevini yitirir ve bireylerde yürüme kaybına kadar giden problemler ortaya çıkmaktadır. Bu problemlerin giderilebilmesi için hasar görmüş eklemin yerine; eklemin geometrik yapısını taklit edecek şekilde tasarlanmış, biyouyumluluğu yüksek, metal ve polietilen malzemelerinden imal edilmiş diz eklem protezleri kullanılmaktadır.

Günümüzde protez kullanım ömürlerinin yaklaşık olarak 20-25 yıl arasinda olması beklenmektedir. Ancak kullanım şartları ve cerrahi operasyonun başarı oranına göre bu süre 10-12 yıla kadar düşmektedir. $\mathrm{Bu}$ nedenle diz eklem protez bileşenlerinde meydana gelen aşınmaların boyutlarının kullanım şartlarına göre belirlenebilmesi protez ömürlerinin tahmini açısından açısından önemlidir. Literatürde diz eklem protezlerinin ömürlerinin belirlenmesinde üç farklı yöntemleri kullanılmaktadır. Bunlar invivo testler, in-vitro testler ve sonlu elemanlar analizi ile gerçekleştirilen testlerdir. In-vivo testler vücut ortamında gerçekleştirildiğinden dolayı hem maliyetli hem de hazırlanması zor bir test yöntemidir. Sonlu elemanlar analizi ile gerçekleştirilen testlerde ise protezlerde meydana gelebilecek beklenmedik hataların gözlemlenmesi mümkün olmamaktadır. In-vitro testleri ise vücut ortamını taklit eden ortamlarda gerçekleştirilen testlerdir. Literatürde de yaygın olarak in-vitro ortamında gerçekleştirilen aşınma testlerinin yapıldığı görülmektedir (Tablo 1).

Literatürde UHMWPE insert bileşeninde meydana gelen yüzey kusurlarının araştırılması üzerine yapılan çalışmalar incelendiğinde genel olarak partikül yığılmaları, çizikler, çukurcuk aşınmaları, delaminasyon ile karşılaşıldığ 1 görülmüştür (Lancin vd., 2007; Flannery vd., 2008; Schwenke vd., 2009; Willing ve Kim, 2009; Affatato vd., 2011; Abdel-Jaber vd., 2015). Gerçekleştirilen testlerin bir kısmı ISO 14243 aşınma test standardına uygun olarak gerçekleştirildiği görülmektedir (Lancin vd., 2007; Affatato vd., 2011; Abdel-Jaber vd., 2015). Diğer çalışmalarda ise standart hareketlerinin dışına çıkılarak testler gerçekleştirilmiştir (Flannery vd., 2008; Willing ve Kim, 2009). Ancak aşınma testleri için kullanılan diz simülatörlerinde çoğunlukla eklem hareketine yardımcı kas, tendon ve bağların etkisi göz ardı edilerek çalışmalar gerçekleştirilmiştir. Yumuşak doku davranışı sergileyen simülatör çalışmalarında ise diz ekleminin sadece tek bir hareket çiftine uygulandığı görülmektedir (Lancin vd., 2007; Schwenke vd., 2009). Bu durum sonucunda da elde edilecek aşınma verileri tam olarak esas diz eklem hareketine uygun olmayan testler sonuçları elde edilmekte ve protez ömürlerinin tespitinde hatalar meydana gelmektedir.

Tablo. 1 Literatür çalışmaları

\begin{tabular}{|c|c|c|c|c|c|}
\hline Yazar & Simülatör hareketleri* & $\begin{array}{c}\text { Çevrim } \\
\text { (milyon) }\end{array}$ & $\begin{array}{c}\text { Yumuşak doku } \\
\text { davranış1 }\end{array}$ & Aşınma tipi & $\begin{array}{c}\text { Kütle kayb1 } \\
(\mathrm{mg})\end{array}$ \\
\hline Lancin vd. (2007) & İ/D, Ö/A, T.D., E.K. & 2.5 & $\mathrm{O} / \mathrm{A}$ & Çukurcuk & 32 \\
\hline Flannarry vd. (2008) & Ö/A, İ/D, E.K. & 2 & - & $\begin{array}{c}\text { Çizik } \\
\text { Delaminasyon }\end{array}$ & 5.4 \\
\hline Schwenke vd. (2009) & $\begin{array}{c}\dot{\mathrm{I}} / \mathrm{D}, \mathrm{T} . \mathrm{D} ., \mathrm{O} / \mathrm{A}, \mathrm{S} / \mathrm{S}, \\
\text { V/V }\end{array}$ & 5 & T.D. & $\begin{array}{c}\text { Çukurcuk } \\
\text { Delaminasyon } \\
\text { Çizik }\end{array}$ & 70 \\
\hline Willing ve Kim (2009) & $\begin{array}{c}\mathrm{O} / \mathrm{A}, \mathrm{I} / \mathrm{D}, \mathrm{S} / \mathrm{S}, \mathrm{T} . \mathrm{D} . \\
\mathrm{A} / \mathrm{A}\end{array}$ & 3.5 & - & $\begin{array}{l}\text { Çukurcuk } \\
\text { Çizik }\end{array}$ & 50 \\
\hline Affatato vd. (2011) & İ/D, Ö/A, T.D., E.K. & 3 & - & Çukurcuk & 4.5 \\
\hline Abdel-Jaber vd. (2015) & Ö/A, İ/D, T.D., E.K. & 5 & - & Çizik & 20.2 \\
\hline
\end{tabular}

*ذ̇I/D: İçe/Dışa, Ö/A: Öne/Arkaya, T.D.: Tibial Dönme, S/S: Sağa/Sola, E.K.: Eksenel Kuvvet

Bu çalışmada da ISO 14243 test standardına uygun olarak üretilen tek istasyonlu diz eklem aşınma test simülatörü ile UHMWPE materyalinde tekrarlı yükler altında meydana gelen aşınma durumları incelendi. Testler gerçekleştirilirken literatürden farklı olarak eksenel kuvvet ve öne-arkaya hareketinde kas, tendon ve yumuşak doku davranışı sergileyebilmesi için yay kullanıldı. 


\section{Materyal ve Metot}

\subsection{Materyal}

Diz eklem protezi kendi içerisinde üç ana bileşenden oluşmaktadır. Bunlar CoCrMo alaşımından döküm yoluyla üretilen femur ve tibia bileşenleri ve UHMWPE polimer malzemesinden üretilen insert bileşenidir (Şekil 1). Bu çalışmada da yaygın olarak tercih edilen size beş bağ koruyan diz eklem protez bileşenleri kullanıldı.

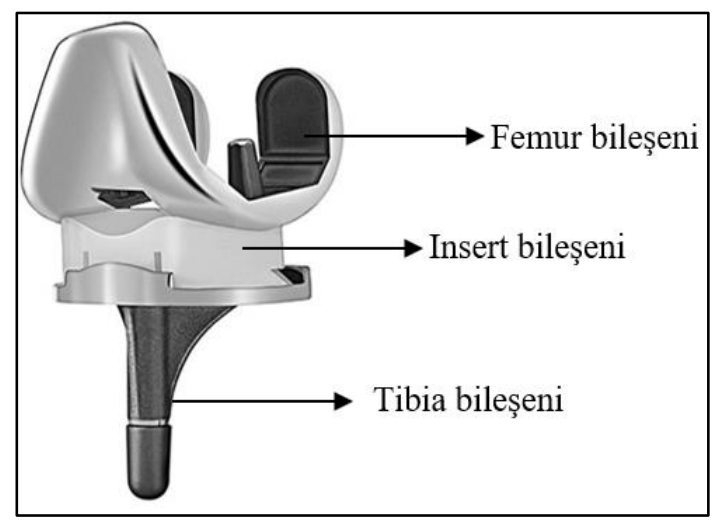

Şekil. 1 Diz eklem protezi

Aşınma testlerinin gerçekleştirilmesi için ISO 14243 aşınma test standardında yer alan içe-dışa (I/D) bükülme, öne-arkaya (Ö/A) hareket, eksenel kuvvet ve tibial dönme olarak adlandırılan dört farklı zit hareket çiftini uygulayabilen tek istasyonlu diz eklem protezi aşınma test simülatörü kullanıldı (Şekil 2). Simülatörde Ö/A ve eksenel kuvvet hareketlerinin uygulanabilmesi için dairesel hareketi doğrusal harekete çeviren lineer aktüatörler kullanıldı. Ö/A hareketinde maksimum $5.7 \mathrm{~mm}$ 'lik yer değiştirme, eksenel kuvvette ise maksimum $2600 \mathrm{~N}$ kuvvet değeri elde edilecek şekilde sınırlandırıldı. İ/D bükülme ve tibial dönme hareket çiftlerinde ise servo motor kullanılarak İ/D hareketinin açısal yer değiştirme değeri maksimum $58^{\circ}$, tibial dönme hareketinin ise $5.2^{\circ}$ olarak sinırlandırıld 1 .

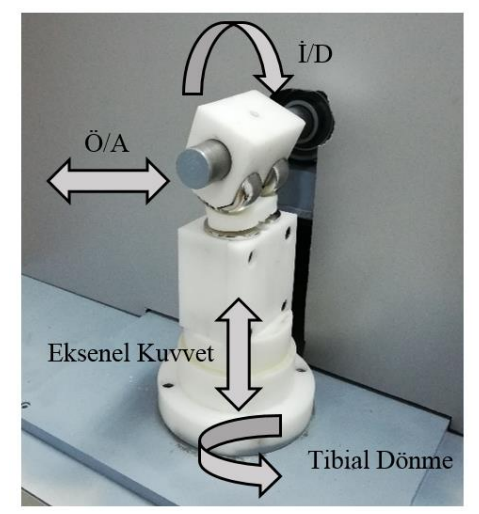

Şekil. 2 Tek istasyonlu diz eklem protezi aşınma simülatörü

\subsection{Metot}

Aşınma testleri literatürde gerçekleştirilen çalışmalar dikkate alınarak üç milyon çevrim için gerçekleştirildi. Test için uygulanan dört farklı zit hareket çifti için kuvvet ve yer değiştirme değerleri Tablo.2'de verildiği gibidir. Testler gerçekleştirilirken her bir milyon çevrim sonucunda literatürde yapılan çalışmalara uygun olarak UHMWPE insert bileșenin iç (medial) ve dış (lateral) kondillerinden taramalı elektron mikroskobu (SEM) ile 500x-1000x-2500x-5000x büyütmede Şekil 3'de gösterilen bölgelerden görüntüler alındı. Ayrıca meydana gelen belirgin aşınmaların görüntülenmesi için makro görüntü elde edilebilen Euromex marka mikroskop ile görüntüler alındı (Şekil 4). Ayrıca elde edilen aşınma verilerinin doğruluğunun desteklenebilmesi için sonlu elemanlar analizi gerçekleştirildi. Elde edilecek sonuçların hassasiyetinin arttırılabilmesi için iki $\mathrm{mm}$ boyutunda tetragonal mesh (element sayis1 84122, düğüm sayıs1 129473) atıldı. Her bir hareket için gerekli olan açısal ve doğrusal yer değiştirme değerleri Tablo.2'de verilen diz eklem aşınma test simülatöründe uygulanan değerler ile aynı belirlendi.

Tablo. 2 Aşınma test değerleri

\begin{tabular}{cc}
\hline \hline Hareket Varyasyonları & Test Değerleri (max) \\
\hline \hline Öne-Arkaya Hareketi $(\mathrm{mm})$ & 5.7 \\
İçe-Dışa Bükülme Hareketi $\left(^{\circ}\right)$ & 58 \\
Eksenel Kuvvet $(\mathrm{N})$ & 2600 \\
Tibial Dönme $\left(^{\circ}\right)$ & 5.2 \\
\hline \hline
\end{tabular}

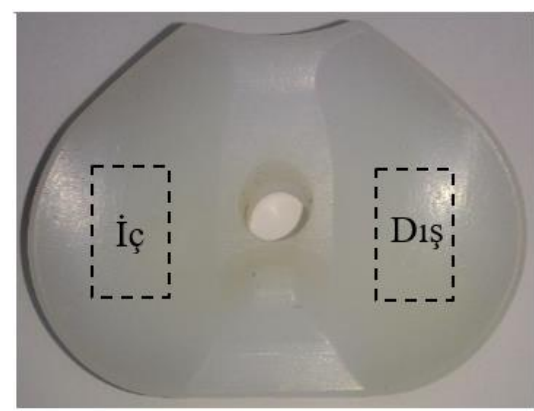

Şekil. 3 SEM ölçüm bölgeleri

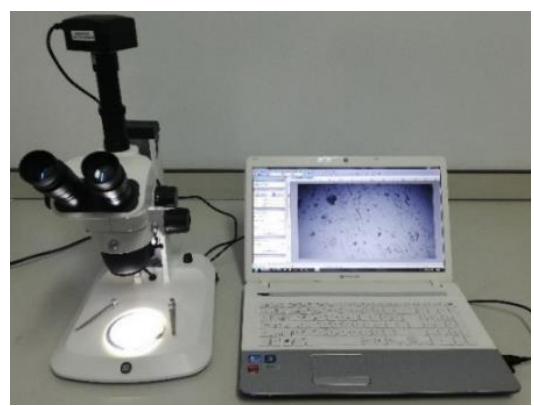

Şekil. 4 Makro görüntülerinin alınması 
Diz eklem protezlerinde kullanım ömrünün belirlenmesinde protez bileşeninde meydana gelen yüzeysel kusurların yanı sıra aşınmaya bağlı olarak ortaya çıkan kütle kayıpları da önemli bir referans oluşturmaktadır. $\mathrm{Bu}$ nedenle test esnasında her bir milyon çevrim sonucunda hassas terazi ile UHMWPE insert bileşenindeki kütlesel kayıplar ölçüldü (Şekil 5).

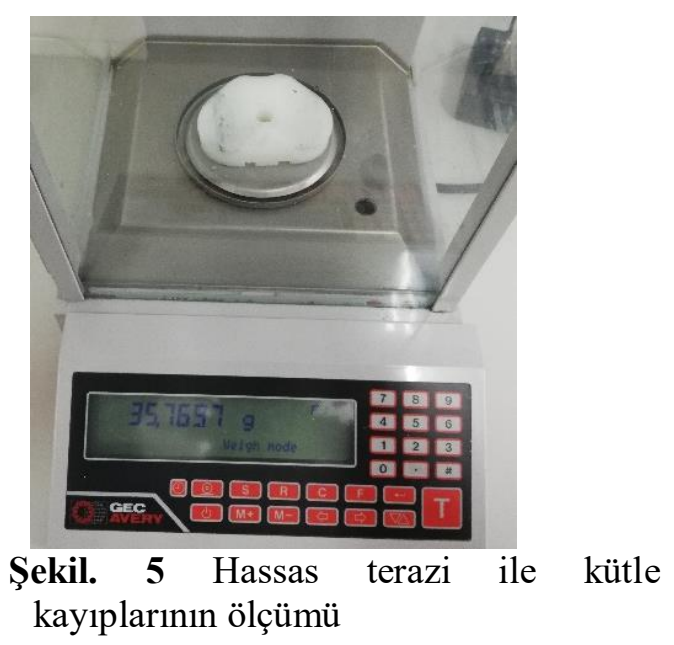

\section{Sonuçlar ve Tartışma}

$\mathrm{Bu}$ bölümde tek istasyonlu diz eklem protezi aşınma test simülatörü ile gerçekleştirilen testler sonucunda UHMWPE insert numunesinde farkl1 çevrim sayılarında meydana gelen yüzey kusurları protez ömrü üzerinde önemli etkileri olduğu belirlendi. Elde edilen mikroskop görüntülerinde benzer sonuçların ortaya çıkmasından dolayı üç milyon çevrim sayısı sonucunda ortaya çıkan aşınma görüntüleri verildi.

\subsection{Yüzey Kusurlart}

İnsert kondillerinden alınan mikroskop görüntülerinde belirgin bir şekilde çukurcuk aşınmalarının meydana geldiği görüldü (Şekil 6). Kendi içerisinde üç aşamalı olarak gerçekleşen bu aşınma tipinde ilk olarak yüzey altında Hertz basınc1 olarak adlandırılan küçük boyutlu basınçlar oluşmaktadır. Meydana gelen değişken basınç değerleri sonucunda yüzeye yakın bölgelerde kılcal çatlaklar oluşmaktadır. Alınan SEM görüntülerinde de kondil yüzeylerinde kılcal çatlakların oluştuğu görüldü (Şekil 7). Kılcal çatlakların oluşum aşamasından sonra farklı yönlerde insert bileşenine etki eden çok yönlü ve değişken kuvvetler sonucunda kılcal çatlaklar giderek büyümekte ve son aşamada da yüzeyden tabaka halinde parçacıklar kopmaya başlamaktadır (Lombardi vd., 2008; Wright ve Goodman, 2001; Shi, 2007).

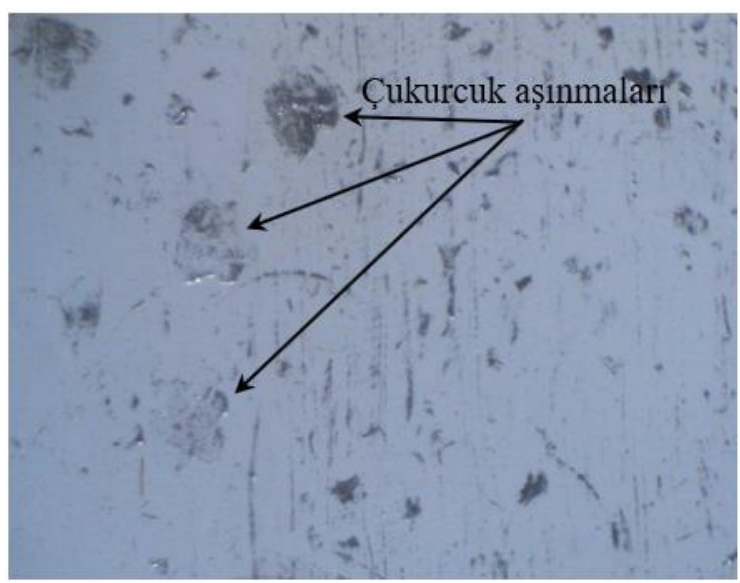

Şekil. 6 Çukurcuk aşınması

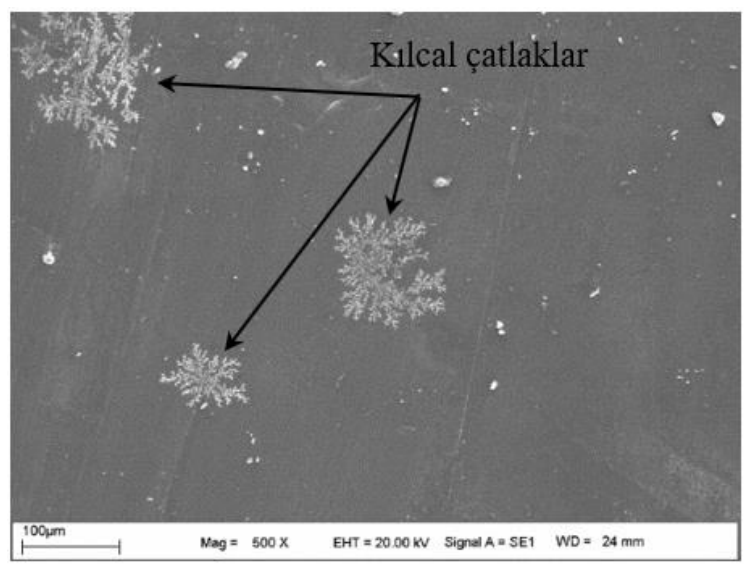

Şekil. 7 Kılcal çatlaklar

UHMWPE insert bileşeninin iç ve diş kondillerinin ön (anterior) bölgelerinden alınan mikroskop görüntülerinde belirgin aşınma izlerinin oluşumuna rastlandı (Şekil 8). Diz ekleminin biyomekaniğinden kaynaklı olarak içedışa bükülme hareketi esnasında tibia eklemi geriye doğru kayma eğilimi göstermektedir. $\mathrm{Bu}$ davranış literatürde "femoral geri yuvarlanma", hareketi olarak adlandırılmaktadır. İçe-dışa bükülme hareket aralığının artışı ile eksenel kuvvet ve öne-arkaya hareketinden kaynaklı olarak anterior bölgelere daha fazla yük binmektedir. Literatürde UHMWPE insert bileşenin aşınması üzerine yapılan çalışmalarda da iç ve diş kondillerin ön bölgelerinde deformasyonların meydana geldiği görülmektedir (Abdelgaied vd., 2011; Cheng ve Hsiau, 2010). Nitekim diz eklem protezlerinin sonlu elemanlar analizi sonucunda elde edilen verilerde de insert bileşeninin ön (anterior) bölgesinde eş değer gerilmelerin ve kontak basınç dağılımlarının yoğunlaştı̆̆ını gösterdi (Şekil 9).

UHMWPE malzemesinin kondil yüzeylerinde yığılmış granül partiküllerinin Ö/A hareket yönünde yoğun olarak oluştuğu görüldü (Şekil 10). 


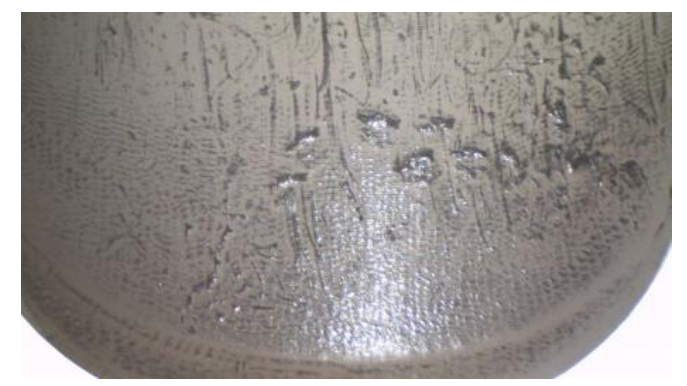

(a)

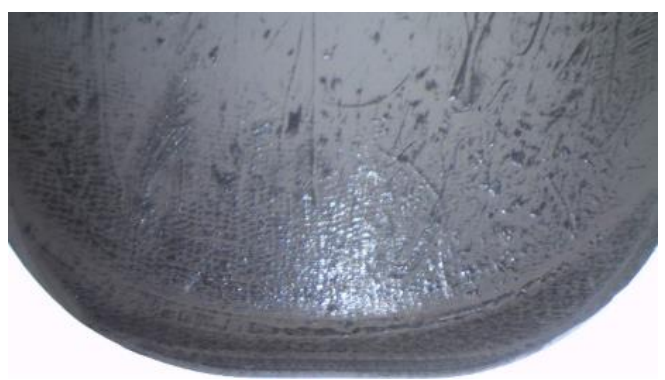

(b)

Şekil. 8 Ön (anterior) bölge aşınması; a) iç (medial), b) dış (lateral)

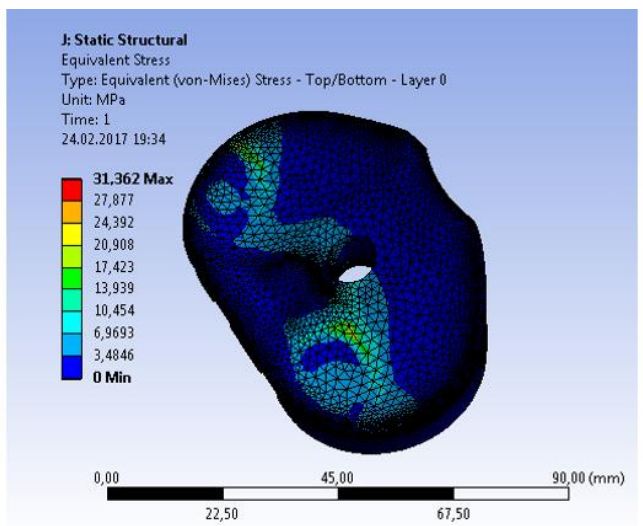

(a)

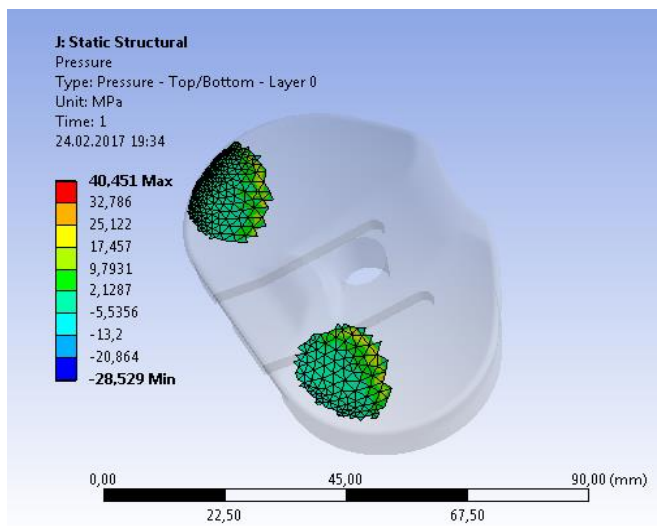

(b)

Şekil. 9 Diz eklem protezi sonlu elemanlar analizi; a) eş değer gerilemeler, b) kontak basınç değerleri

$\mathrm{Bu}$ yap1 birbiri ile etkileşime giren ve birbiri üzerinde biriken iki veya daha fazla partikülün bir sonucu olarak ortaya çıkmaktadır (Liu vd., 2015). Kullanıma bağlı olarak deforme olabilirliğinin sürekli artması ile partikül-alt katman (UHMWPE polimer matris) ara yüzünde oluşan bu yapının temel sebebi polimer matrislerinin bir araya toplanması ile açıklanabilir. Sonuç olarak bu durum üniform olmayan özellikle bir oluşum ile sonuçlanmaktadır. Nitekim literatürde de UHMWPE aşınması üzerine yapılan çalışmalarda elde edilen sonuçlarda benzer durumun oluştuğunu görülmektedir (Liu vd., 2015; Villa vd., 2004).

Alınan SEM görüntülerinde Ö/A hareketi ile aynı yönlü çiziklerin oluştuğu görüldü (Şekil 11). Çizik oluşumunda polietilen ve metal malzemelerden kopan partiküllerin yanı sıra tekrarlı yük ile gevşeyen kemik çimentosundan ayrılan partiküller insert ve femur bileşeninin arasına girerek Ö/A ve İ/D hareketinin birleşimi ile ortaya çıkan bileşke kuvvet ile yüzey üzerinde hem baskiya hem de sürtünmeye maruz kaldığından belirgin çizikler oluşturmaktadır. Ayrıca SEM görüntülerinde de insert bileşeninin iç ve dış kondillerinde de farklı boyutlarda çiziklerin oluştuğu görüldü. Çiziklerin kalınlıkları ölçüldüğünde lateral bölgede ortalama $7.1 \mu \mathrm{m}$ iken medial bölgede ortalama $11.7 \mu \mathrm{m}$ olduğu görülmektedir (Şekil 11a-11b).

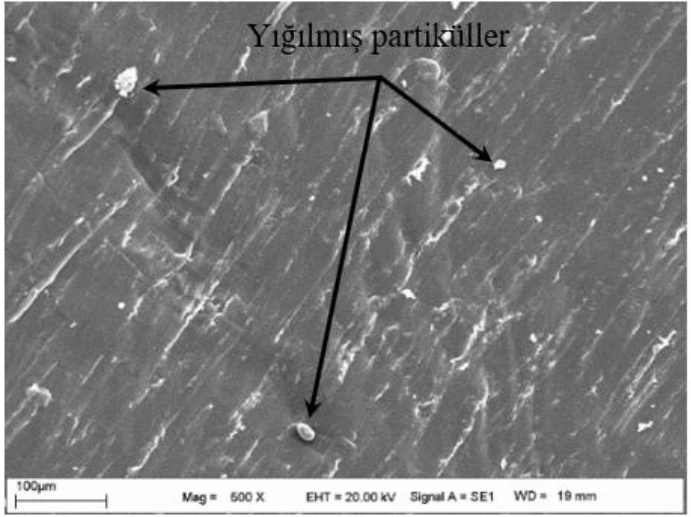

Şekil. 10 Yığılmış granül partikülleri

Meydana gelen bu fark vücut mekanik aksından kaynaklı yük dengesizliğinden kaynaklı olarak oluşmaktadır. Nitekim UHMWPE malzemesinde meydana gelen çizik oluşumları ile ilgili yapılan çalışmalarda da bu durum desteklenmektedir (Flannery vd., 2008).

Femur bileşen kondillerinden alınan SEM görüntülerinde de doğrusal ve çok yönlü çiziklere rastland1 (Şekil 12a-12b). Böylece insert kondillerinde oluşan çiziklerin femur bileşeni ile ilişkili olarak meydana geldiği görüldü. Femur bileşeninde oluşan doğrusal çizikler içe-dışa bükülme hareketi ile çok yönlü çiziklerin ise hem öne-arkaya hareketi hem de tibial dönme hareketinden kaynaklı olarak oluştuğu belirlendi. 


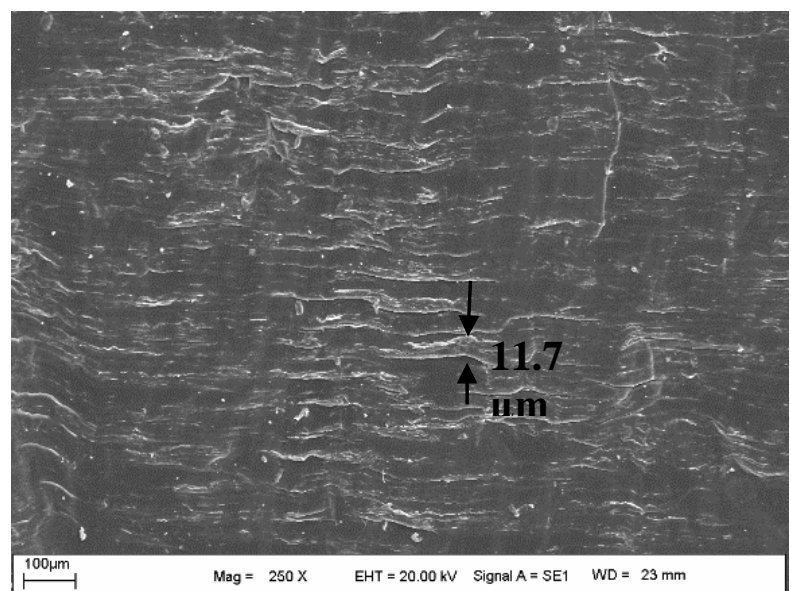

(a)

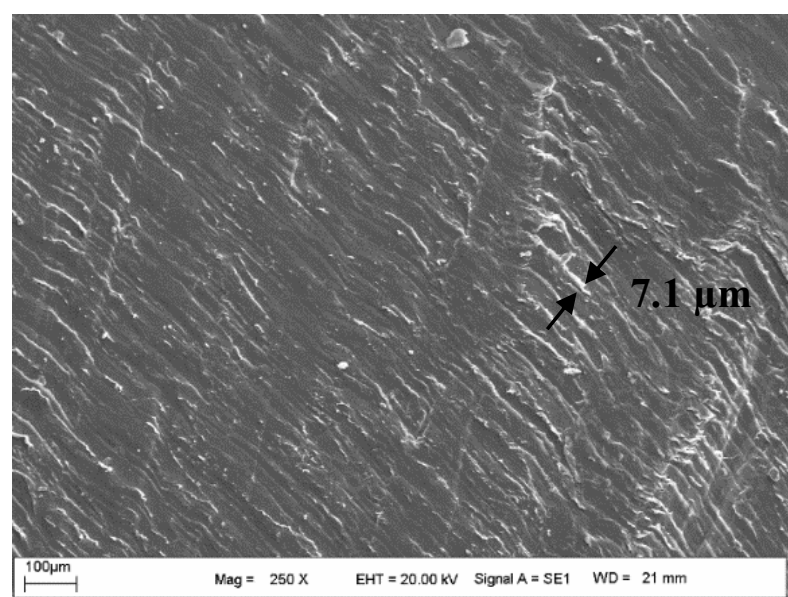

(b)

Şekil. 11 Çizikler: a) iç (medial) kondil, b) dış (lateral) kondil

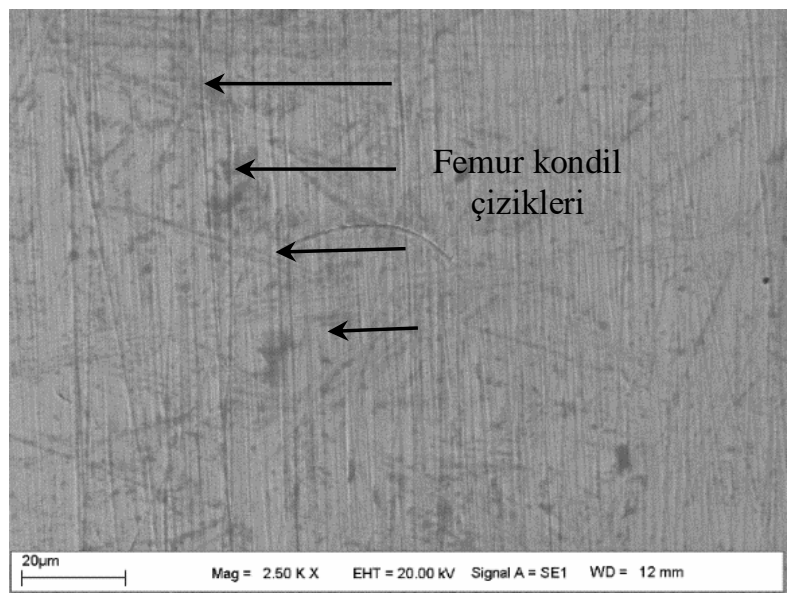

(a)

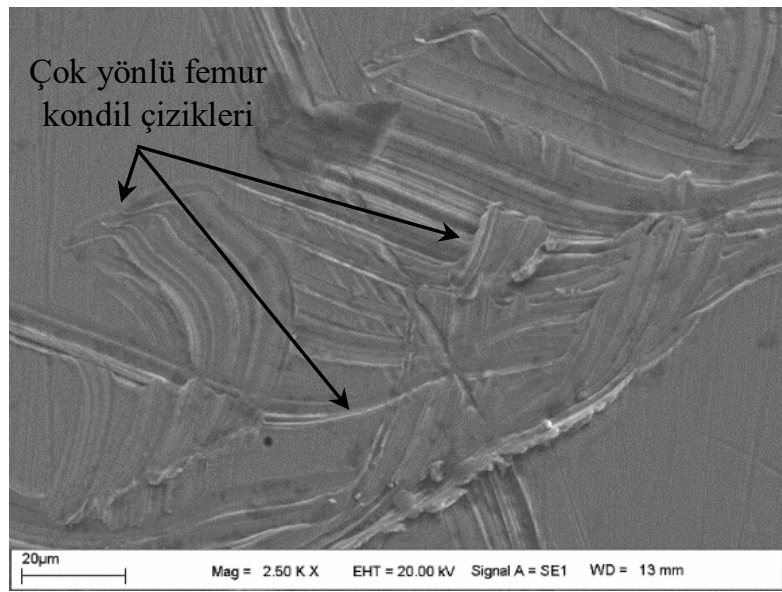

(b)

Şekil. 12 Femur bileşen çizikleri, a) doğrusal, b) çok yönlü

\subsection{Kütle Kaybı}

Diğer yandan meydana gelen partikül kopmaları sonucunda UHMWPE malzemesinde kütle kayıpları oluşmaktadır. Kütle kayıplarının bilinmesi de protez ömrünün belirlenmesinde önemli bir parametredir. $\mathrm{Bu}$ nedenle üç farkl1 UHMWPE malzemesinden, üç farklı çevrim sayısı sonucunda hassas teraziden alınan ölçümler sonucunda kütle kayb1 maksimum $3.91 \mathrm{mg}$ olarak ölçüldü (Şekil 13). Aşınmanın birinci aşamasında kütle kaybı ani ve değişken yükler ve bu yüklere bağlı olarak oluşan yorulma ile hızlı bir şekilde artmaktadır. İkinci aşamada ise aşınan bölgelerdeki hem çukurcuk aşınmaların hem de çukurcuk aşınmasının oluşumunda önemli rol oynayan kılcal çatlakların giderek büyümesi sonucunda kütledeki kaybın giderek artışına sebep olmaktadır.

Son aşamada ise tekrarlı yüklere bağlı yorumların artışı yüzey kusurlarındaki artışı daha fazla tetiklemekte ve kütle kaybı birinci ve ikinci aşamaya göre daha hızlı gerçekleştiği görülmektedir.

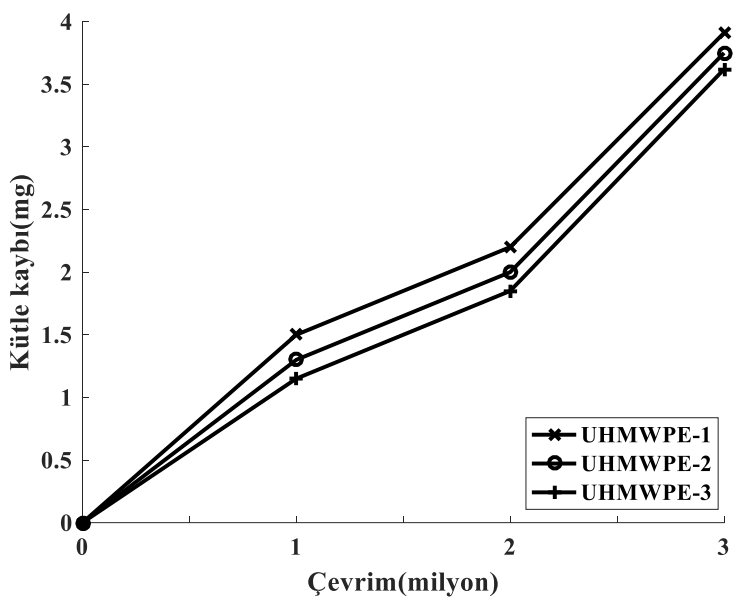

Şekil. 13 UHMWPE insert bileşen kütle kaybı

Sonuç olarak bu durum değişken olarak farklı eksenlerde sürekli uygulanan kuvvetlerin etkisi ile gerilmeler sonucunda kopan partiküllerin sayısında artış sonucunu ortaya çıkmaktadır (Willing ve Kim, 2009; Wright ve Goodman, 2001). 


\section{Genel Sonuçlar}

$\mathrm{Bu}$ çalışmada diz eklem protezlerindeki UHMWPE malzemesinin periyodik yükler altında aşınma performanslarını gözlemlemek için testler gerçekleştirilerek, UHMWPE malzemesindeki hata mekanizmaları incelendi. Elde edilen deneysel veriler aşağıda sıralandığı gibidir:

1. Test çevrim sayısının artmasına bağlı olarak UHMWPE malzemesinden aşınma sonucunda meydana gelen kütle kaybının arttığı görülmüştür.

2. Çevrim sayısının artmasına bağlı olarak UHMWPE malzemesinin yüzeylerinde yorulma aşınmalarının giderek belirginleştiği görüldü. Ayrıca, femoral geri yuvarlanma hareketinden dolayı ön (anterior) bölgedeki aşınmaların arka (posterior) bölgeye oranla daha yoğun gerçekleştiği görüldü.

3. İç (medial) bölgede meydana gelen yorulma aşınmalarının dış (lateral) bölgeye göre daha fazla olduğu görüldü.

4. Ö/A hareket yönünde yığılmış granül partiküllerinin oluştuğu görüldü.

5. İ/D bükülme hareket aralığının artışı ile yüzeyde meydana gelen aşınmaların arttığı görüldü.

6. Çevrim sayısının artışına bağlı olarak insert numunelerinde kütle kayıplarının arttığı görüldü.

Sonuç olarak, UHMWPE insert bileşeninin aşınma testleri ile cerrahi operasyon öncesinde aşınma bölgeleri net bir şekilde anlaşılabilmektedir. Böylece protez bileşenlerinde farklı tasarımlar ve üretim yöntemleri ile gerçekleştirilecek imalat aşamaları sayesinde protezlerin kullanım ömürleri arttırılabilmektedir. Ayrıca, cerrahi operasyonun başarısı arttırılarak hasta sağlı̆g a açısından olumlu sonuçlar elde edilebilecektir.

\section{Kaynaklar}

Abdelgaied, A., Liu, F., Brockett, C., Jennings, L., Fisher, J. ve Jin, Z., 2011. Computational wear prediction of artificial knee joints based on a new wear law and formulation. Journal of Biomechanics. 44, 1108-1116.

Abdel-Jaber, S., Belvedere, C., Leardini, A. ve Affatato, S., 2015. Wear simulation of total knee prostheses using load and kinematics waveforms from stair climbing. Journal of Biomechanics. 48, 3830-3836.

Affatato, S., Spinelli, M., Lopomo, N., Grupp, T. M., Marcacci, M. ve Toni, A., 2011. Can the method of fixation influence the wear behaviour of $\mathrm{ZrN}$ coated unicompartmental mobile knee prostheses. Clinical Biomechanics. 26(2), 152158.

Cheng, H., J. ve Hsiau, S., S., 2010. The study of granular agglomeration mechanism. Powder Technology. 199, 272-283.

Flannery, M., McGloughlin, T., Jones, E. ve Birkinshaw, S., 2008. Analysis of wear and friction of total knee replacements: Part I. Wear assessment on a three station wear simulator. Wear. 265, 999-1008.

ISO (2014). Loading and displacement parameters for wear-testing machines with displacemet control and corresponding environmental conditions for test, ISO 14243-3: International Organization for Standardization

Lancin, P., Essner, A., Yau, S., S. ve Wang, A., 2007. Wear performance of 1900 direct compression molded, 1020 direct compression molded, and 1020 sheet compression molded UHMWPE under knee simulator testing. Wear. 263, 10301033.

Liu, A., Richards, L., Bladen, C., L., Ingham, E., Fisher, J. ve Tipper, J., L., 2015. The biological response to nanometer sized polymer particles. Acta Biomaterialia. 23, 38-51.

Lombardi, A., V., Ellison, B., S. ve Berend, K., R., 2008. Polyethylene Wear Is Influenced by Manufacturing Technique in Modular TKA. Clinical Orthopaedics and Related Research. 466.

Schwenke, T., Orozco, D., Schneider, E. ve Wimmer, M., A., 2009. Differences in wear between load and displacement control tested total knee replacements. Wear. 267, 757-762.

Shı, J., 2007. Finite Element Analysis Of Total Knee Replacement Considering Gait Cycle Load and Malalınment, Ph.D. Thesis, Wolverhampton University England, 142s.

Villa, T., Migliavacca, F., Gastaldi, D., Colombo, M. ve Pietrabissa, R., 2004. Contact stresses and fatigue life in a knee prosthesis: comparison between in vitro measurements and computational simulations. Journal of Biomechanics. 37 45-53.

Willing, R. ve Kim, I., Y., 2009. A holistic numerical model to predict strain hardening and damage of UHMWPE under multiple total knee replacement kinematics and experimental validation. Journal of Biomechanics, 42(15), 2520-2527.

Wright, T., M. ve Goodman, S., B., 2001a.What design factors influence wear behavior in total knee replacement. American Academy of Orthopaedic Surgeons (Ed.). Implant Wear in Total Joint Replacement. p.224. 